\title{
ANTIBIOTICOTERAPIA E SUAAUTOMEDICAÇÃO: PRÁTICA COMUM ENTRE ESTUDANTES DO CURSO DE BIOMEDICINA DE INSTITUTO DE ENSINO SUPERIOR
}

\author{
ROSSI, Isabella Leone. Biomédica. E-mail: isaleonerossi@ hotmail.com. \\ SANTOS, Michelle Caroline dos. Biomédica. \\ CRISCI, Ana Rosa. Mestre. Centro Universitário Barão de Mauá, Ribeirão Preto-SP Rua: Ramos de \\ Azevedo, 425, Jardim Paulista. CEP 14090-180, Ribeirão Preto-SP.
}

\begin{abstract}
RESUMO
O hábito da automedicação de antibióticos contribui para o mecanismo de resistência bacteriana, sendo um problema de saúde pública mundial que deve ser prevenido. O universitário, como futuro profissional da saúde, é cobrado no sentido de orientar uma conduta e informar quanto ao uso de antimicrobianos no que se refere ao agente causal, ao sítio de infecção e à gravidade da doença. Neste estudo, verificou-se, através de um questionário, o perfil dos acadêmicos ingressantes e concluintes do curso de biomedicina de uma instituição de nível superior, comparando-se os resultados obtidos. Trata-se de um estudo descritivo com abordagem quantitativa dos dados (frequência relativa - \%) através de questionário autoaplicável, e contendo 13 questões de múltipla escolha armazenadas no banco de dados no programa Excel. A amostra foi composta por 132 alunos de graduação do curso de Biomedicina desse centro universitário. Dentre os acadêmicos ingressantes, a compra do antibiótico é influenciada principalmente pela experiência própria com o fármaco, o que não se repete com concluintes, que preferem procurar e seguir orientação médica. Assim, 91,8\% dos concluintes acreditam que a automedicação pode trazer danos à saúde. Em relação ao consumo de anti-inflamatórios, analgésicos e antitérmicos antes do uso do antibiótico, $67 \%$ dos iniciantes disseram que fazem a utilização destes medicamentos, contra $70 \%$ dos concluintes que também a fazem. Portanto, conclui-se que informações sobre os perigos da automedicação são fornecidos nas disciplinas de microbiologia e farmacologia, disciplinas estas ainda não cursadas pelos ingressantes e desconhecidas pela população em geral, que recorre à automedicação devido à falta de conhecimento. Para reverter este quadro, é necessária uma maior exposição na mídia sobre práticas educativas, riscos, benefícios, e explicações sobre bactérias multirresistentes.
\end{abstract}

PalaVras-ChaVe: Automedicação; Antibioticoprofilaxia; Acadêmicos.

ANTIBIOTICTHERAPY AND SELF MEDICATION: A COMMON PRACTICE AMONG STUDENTS OF A BIOMEDICINE COURSE IN A HIGHER EDUCATION INSTITUTION

\section{Abstract}

Self-medication habit of antibiotics contributes to the bacterial resistance mechanism, which is a global public health problem that must be prevented. The university student, as a future health professional, is summoned to guide a conduct and report on the use of antimicrobials regarding the casual agent, the site of infection and the severity of the disease. In this study, it has been verified, through a questionnaire, the profile of freshmen and academic students who are majoring in Biomedical Science in an institution of highereducation, comparing the results obtained. It is a descriptive study with quantitative data approach (relative frequency $\%$ ) through a self-administered questionnaire, and containing 13 multiple choice questions stored in the database 
in Excel. The sample consisted of 132 undergraduate students from the Biomedical Science course from this University Center. Among the freshmen, the purchase of antibiotic is mainly influenced by previous experiences with the drug, what is not repeated by the students that are graduating and prefer to seek and follow medical advice. Thus, $91.8 \%$ of trainees believe that self-medication may be harmful to health. Regarding the use of anti-inflammatory, analgesic and antipyretic before the use of antibiotics, $67 \%$ of the entering students said that they take these medications, against $70 \%$ of the senior students that also do it. Therefore, we may conclude that information on the danger of self-medication is provided in the disciplines of microbiology and pharmacology, which have not been studied by the freshmen and is unknown by the general population, that appeals to self-medication due to the lack of knowledge. To reverse this situation, it is necessary a greater media exposure on educational practices regarding the risks, the benefits, and elucidation about multi-resistant bacteria.

KEYwORDs: Automedication; Antibiotic-prophylaxis; Undergraduate students.

\section{INTRODUÇÃ̃o}

A facilidade do acesso a medicamentos devido ao número elevado de farmácias e drogarias, a propaganda que muitas vezes induz e incentiva o consumo de determinado medicamento, que nem sempre é o indicado para aquela necessidade, e o acúmulo de medicamentos nas residências são fatores de risco para a prática da automedicação (BRASIL, 2001).

Segundo Nicolini (2012), os dados da Organização Mundial da Saúde demonstram que as infecções causam $25 \%$ das mortes em todo o mundo e $45 \%$, nos países menos desenvolvidos. O uso de antibióticos para essas situações pode ser calculado como: $\bullet$ Mais de $50 \%$ das prescrições se mostram inapropriadas; $\bullet$ 2/3 dos antibióticos são usados sem prescrição médica em muitos países; • Mais de $50 \%$ do orçamento com medicamentos são destinados aos antimicrobianos; • $50 \%$ dos consumidores compram o medicamento para 1 dia e $90 \%$ compram-no para período igual ou inferior a 3 dias.

Esses dados fazem referência à automedicação, que é definida como o uso de medicamentos sem a prescrição, orientação e/ou acompanhamento do médico ou dentista, assim, esta prática pode não resultar na cura da patologia, mascarando apenas os sintomas, além de poder provocar intoxicação farmacológica e dependência física ou psíquica (OLIVEIRA, 2004).

Em 2002, segundo dados da Agência Nacional de Vigilância Sanitária, havia 15.831 medicamentos em comercialização no Brasil, com um volume total de unidades de medicamentos comercializados no mercado varejista de 1.277.336.635. Esse excesso de consumo eleva o número de intoxicações e efeitos adversos; afinal, é sabido que todo medicamento apresenta um potencial de risco. A automedicação, assim como a medicação leiga feita pelos familiares sem orientação médica, constituem circunstâncias intencionais, e não deveriam ser consideradas como acidentais (LESSA e BOCHNER, 2008).

Fica evidente que o hábito da automedicação de antibióticos pode ter como consequência efeitos indesejáveis, enfermidades iatrogênicas e mascaramento de doenças evolutivas, representando, portanto, problema a ser prevenido. O seu uso de forma inadequada tem contribuído maciçamente para o mecanismo de resistência bacteriana em todo o mundo, sendo, portanto, um problema de saúde pública mundial (AQUINO et al., 2010).

Sabe-se que a administração desorientada e consecutiva dos antibióticos leva à seleção natural de bactérias de todo o organismo, pois agem em diferentes sítios; assim, há o surgimento de bactérias mutantes/ resistentes (ESTEVAM, 2013). Além disso, a resistência gerada é uma característica genética, relacionada principalmente aos plasmídeos ou por mutação durante o processo de crescimento que resultam em erros na sequência de base do DNA cromossômico (CUNHA, 2011). 
Sendo assim, estudos mostram um elevado índice de automedicação entre acadêmicos dos cursos de saúde, que é o resultado de um conhecimento teóricoprático considerado satisfatório sobre medicamentos, que o aluno adquire durante o curso de graduação. $\mathrm{O}$ estudo de Pinto et al. (2008) revela quais são os medicamentos mais utilizados pelos acadêmicos, sendo os antibióticos $(48,8 \%)$ e anti-inflamatórios $(41,6 \%)$ usados com mais frequência no primeiro período e os ansiolíticos $(48,8 \%)$ e antidepressivos $(5,2 \%)$ pelos acadêmicos do último período; fato relevante também observado foi que a maioria dos acadêmicos do primeiro período $(64,7 \%)$ e do último período $(60,8 \%)$ afirmou ter obtido receita médica desses medicamentos nos últimos 12 meses.

Este artigo teve como objetivo verificar, através da aplicação de um questionário, a prática da automedicação de antibióticos nos acadêmicos do Curso de Biomedicina de uma instituição de ensino superior privado do interior de São Paulo.

\section{Material e Métodos}

O presente estudo foi autorizado pelo Comitê de Ética em Pesquisa do Centro Universitário Barão de Mauá, registrado com o número de protocolo 271.319, divulgado em 14 de maio de 2013.

Os pré-requisitos necessários para a participação da pesquisa foram apontados como: (1) os alunos estarem presentes em sala de aula no dia da coleta de dados; (2) assinaremo Termo de Consentimento Livre e Esclarecido; (3) estarem cursando os $1 .^{\circ}, 3 .^{\circ}, 5 .^{\circ} \mathrm{e}$ 7. ${ }^{\circ}$ semestres do curso de biomedicina.

Para a coleta de dados foi utilizado um questionário autoaplicável, contendo 13 questões de múltipla escolha, que se encontra abaixo. Segundo Lakatos e Marconi (2001), questionário é um instrumento de coleta de dados, constituído por uma série ordenada de perguntas que devem ser respondidas por escrito e sem a presença do entrevistador. Foi enviada uma carta junto ao questionário, explicando o tipo da pesquisa e sua importância, tentando despertar o interesse do recebedor. Os dados obtidos na entrevista foram armazenados em um banco de dados no programa
Excel, sendo utilizada para a análise dos resultados a estatística descritiva (frequência relativa-\%).

\section{QUESTIONÁRIO:}

DATA:

ANO/PERÍODO:

CURSO:

1 - Qual a sua:

Idade

$$
\text { Sexo: M( ) F( ) }
$$

2-Situação Conjugal:

( ) Solteiro ( ) Casado ( ) Divorciado ( ) Amasiado ( ) Outros

3 - Você utiliza antibióticos com que frequência?

( ) Sempre

( ) Quando acho que preciso

( ) Quando tenho infecção no Sistema Respiratório Superior (dor de garganta, sinusite, etc.)

( ) Quando preciso e vou ao médico e ele prescreve.

4- a) Já tomou antibiótico nos últimos 12 meses:

( ) Sim. ( ) Não.

b) O Antibiótico foi prescrito por algum médico nos últimos 12 meses:

( ) Sim. ( ) Não, fiz automedicação.

c) Quantas vezes tomou antibiótico, no período de um ano?

( ) 1 ( ) 2 ( ) 3 ( ) 4 ( ) Mais de 4 vezes ( ) Não sei dizer

5 - Você utiliza antibiótico sob orientação de:
( ) Própria
( ) Mãe e Pai
( ) Médicos e Enfermeiros
( ) Farmacêuticos
( ) Balconistas de farmácias
( ) Amigos
( ) Outros 
6 - Se a orientação for própria, em que se baseia para utilizá-los:

( ) Costume, uso crônico. Consultou uma vez, resolveu o problema e continuou o uso.

( ) Acredito ter conhecimento teórico para me automedicar.

( ) Todos meus familiares usam e sei que resolve meu problema.

7 - Você usa antes do antibiótico outra medicação como: anti-inflamatórios, analgésicos, antitérmicos.

( ) Sim. ( ) Não.

8 - Você utiliza sempre os mesmos antiinflamatórios, analgésicos e/ou antitérmicos quando apresenta os mesmos sintomas:

( ) Sim. ( ) Não. ( ) Uso o que estiver disponível em casa.

9 - O remédio (antibiótico) utilizado sempre está disponível em sua casa:

( ) Sim, procuro sempre tê-los em casa.

( ) Não, mas compro quando preciso, porque sei que ele resolve meu problema.

( ) Não, procuro uma unidade de saúde/médico particular para consultar e pegar receita.

10 - Você acha que a automedicação pode trazer algum dano a sua saúde:

( ) Sim. ( ) Não.

11 - Você acredita que obterá informações que possam ajudá-lo na automedicação, durante o curso?

( ) Sim. ( ) Não.

12 - Quando você faz uso de antibióticos:

( ) Você faz o tratamento até o final (7 dias).

( ) Interrompe o tratamento quando não possui mais sintomas.

13 - Você sabe as consequências do uso incorreto de antibióticos:

( ) Sim. ( ) Não.

\section{Resultados e Discussão}

O presente estudo mostra um dado significativo onde ficou comprovado que $91,8 \%$ dos concluintes acreditam que a automedicação pode trazer danos à saúde (Figura 2). Os resultados (Figura 1) mostraram que, dentre os acadêmicos ingressantes, a compra do antibiótico é influenciada principalmente na experiência própria com o fármaco, o que não se repete entre os concluintes, que preferem procurar e seguir orientação médica, ou seja, quando questionados em que se baseiam para exercer a automedicação, $47 \%$ dos ingressantes do curso disseram que é costume, que consultaram uma vez, houve a prescrição, resolveu-se o problema e, assim, usam sempre que acha ser necessário, e $11 \%$ disseram que sabem que todos os familiares usaram e que resolverá o seu problema. Apenas $2 \%$ disseram que acreditam ter conhecimento teórico para saber fazer a automedicação. Entre aqueles alunos que cursam o último período, $91 \%$ alegaram que seguem a orientação de um médico, 10,8\% disseram que é costume, que consultaram uma vez, houve a prescrição, resolveu-se o problema e, assim, usam sempre que acha ser necessário, e 5\% disseram que sabem que todos os familiares usaram e que resolverá o seu problema. Com isso, 26\% dos ingressantes disseram sofrer influência do pai/mãe, contra $13,5 \%$ dos concluintes. Também há influência dos farmacêuticos, correspondendo a $15,7 \%$ dos ingressantes e a 10,8\% dos concluintes. Em relação ao consumo de anti-inflamatórios, analgésicos e antitérmicos antes do uso do antibiótico, 67\% dos ingressantes disseram que fazem a utilização desses medicamentos, contra $70 \%$ dos concluintes que também a fazem. Quando há o surgimento dos mesmos sintomas de doença, 43,1\% dos ingressantes disseram que usamo anti-inflamatórios/analgésicos/antitérmicos de costume; ou seja, sempre consomem o mesmo medicamento, o que correspondendo aos $43,2 \%$ dos concluintes que também usam o de costume. Porém, na ausência deste, 9,4\% dos ingressantes usam qualquer outro que tenha o mesmo princípio e, assim, apenas $10 \%$ dos concluintes confirmam o mesmo. Ressalta-se que a automedicação também ocorre para 
as demais classes de medicamentos que não o antibiótico, sendo equivalente entre ingressantes que ainda não possuem a base da farmacêutica, microbiológica e imunológica, tanto para os concluintes que obtiveram esses conhecimentos durante as aulas ministradas, demonstrando, ainda assim, o descaso com os perigos da automedicação para outro tipo de princípio ativo.

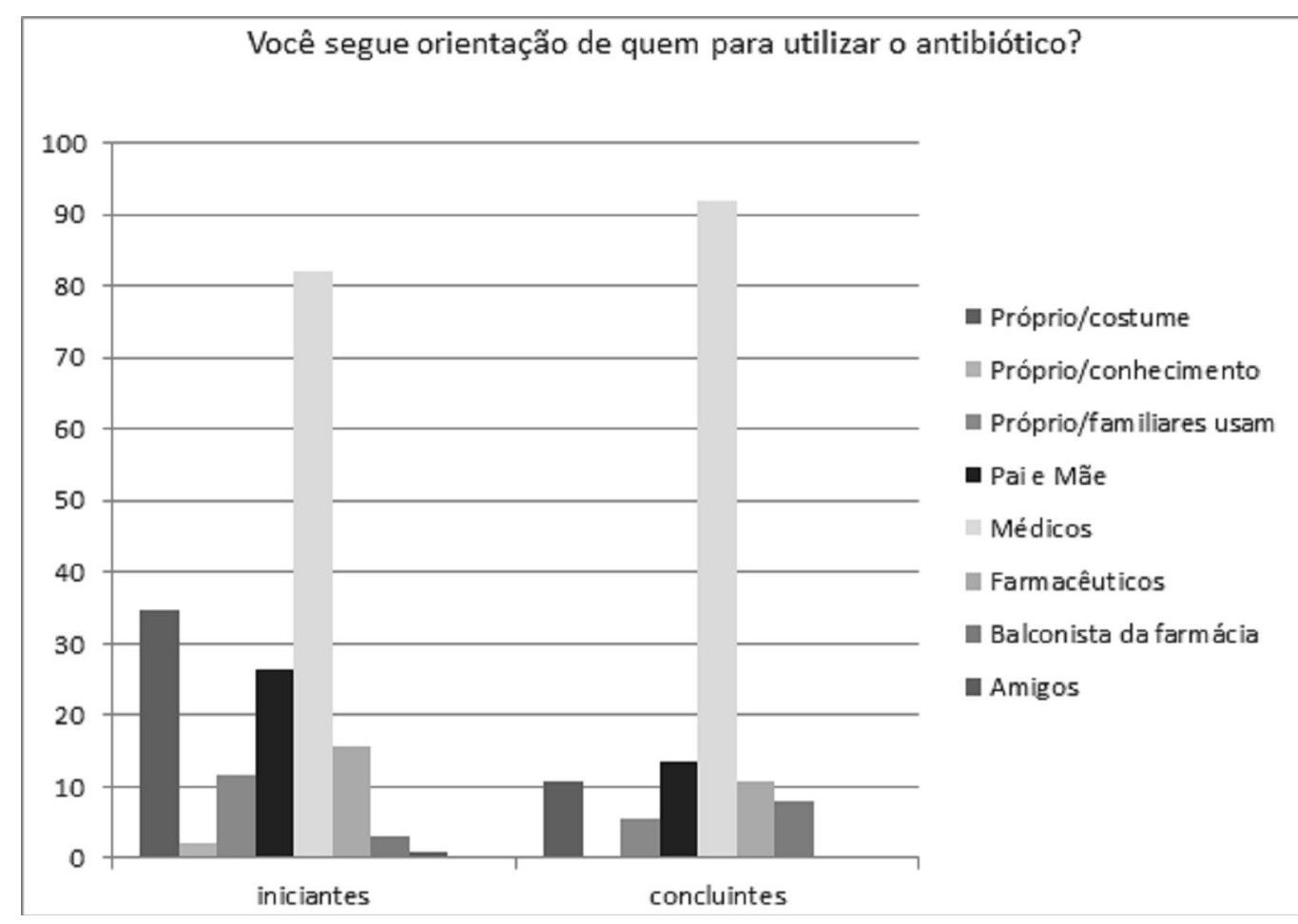

Figura 1 - Comparação sobre o tipo de influência exercida na compra do antibiótico. Fonte: Próprio Autor.

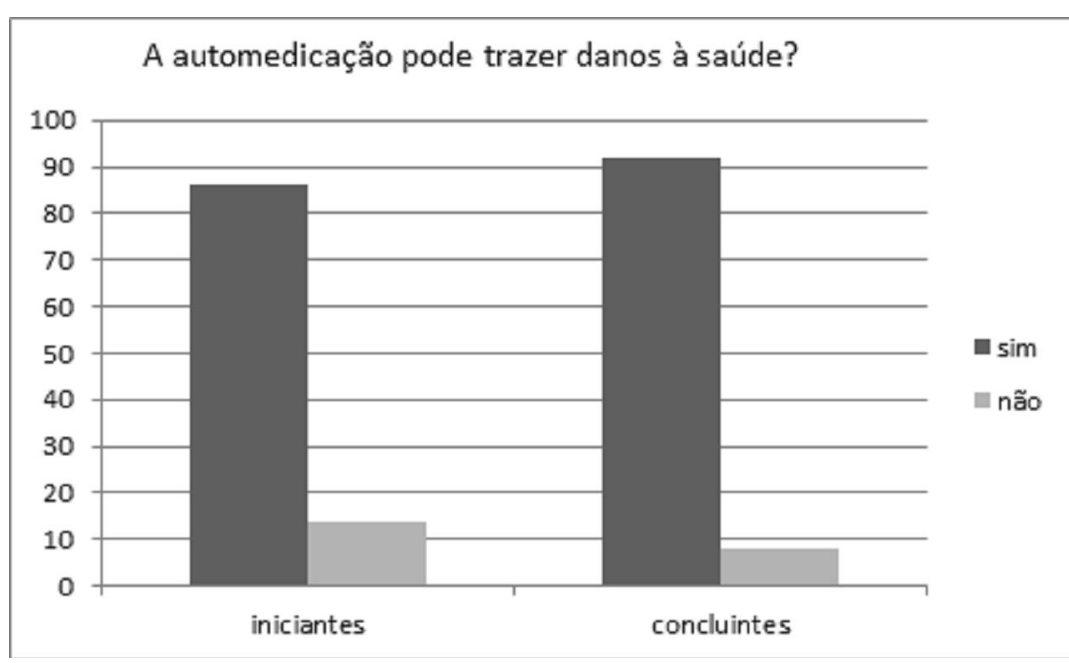

Figura 2-Comparação das respostas sobre os danos da automedicação.

Fonte: Próprio Autor. 
Quando indagados sobre a orientação que seguem para comprar o antibiótico, 38,9\% dos 95 alunos ingressantes disseram que o antibiótico usado nos últimos 12 meses foi prescrito pelo médico, e $35 \%$ não obtiveram prescrição pelo profissional, mas fizeram o uso, o que demonstra uma mínima diferença entre o prescrito e não prescrito (Figura 3). Este dado pode justificar o fato de $31,5 \%$ dos ingressantes alegarem que fazem a automedicação quando apresentam infecção no trato respiratório superior (Figura 4).

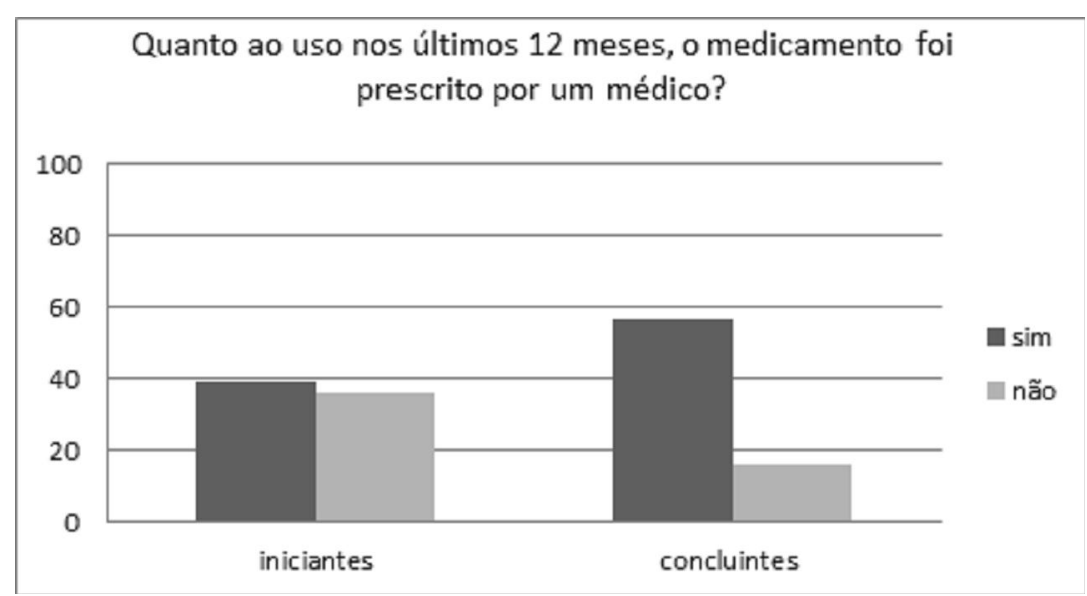

Figura 3 - Comparação sobre a prescrição por médicos.

Fonte: Próprio Autor.

Estabeleceu-se comparação entre ingressantes e concluintes sobre a frequência do uso de antibióticos (Figura 4), tendo entre os ingressantes $1 \%$ respondendo que sempre faz seu uso; $31,5 \%$ usam quando tem infecção no trato respiratório superior, como dor de garganta e sinusite; $47 \%$ quando vão ao médico e este prescreve; e $20 \%$ quando acham que precisam. Já entre os concluintes, $16 \%$ disseram que usam quando têm infecção no trato respiratório superior, como dor de garganta e sinusite; 72,9\% quando vão ao médico e este prescreve; e $10 \%$ quando acham que precisam utilizar. 


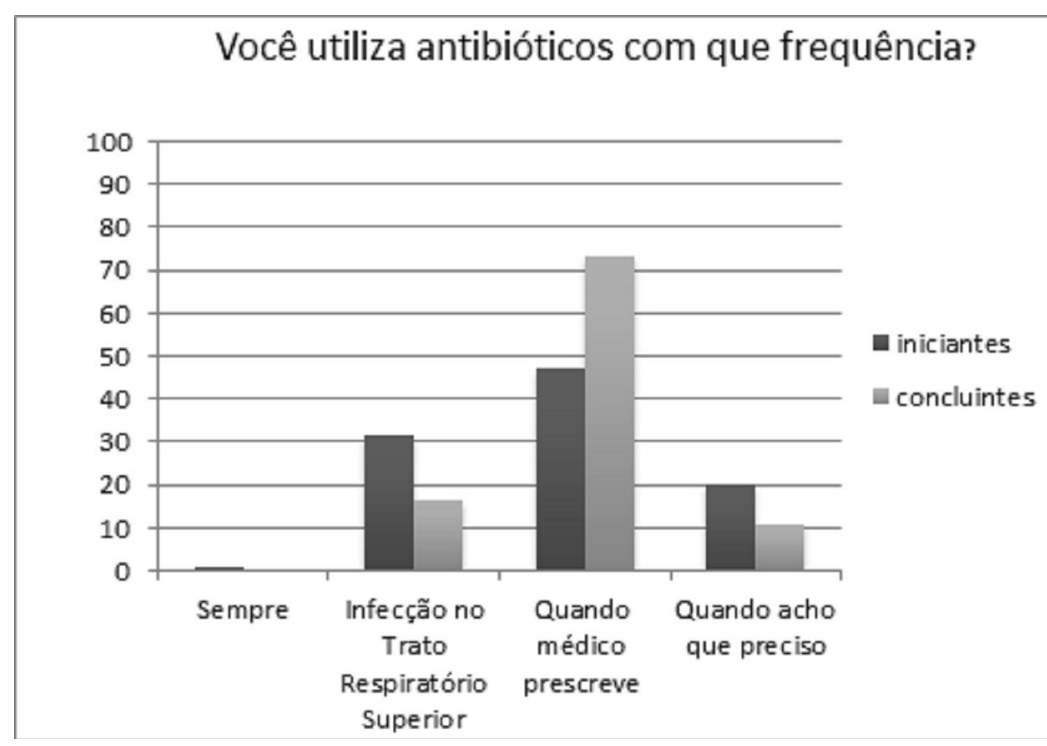

Figura 4 - Comparação sobre a frequência de uso do antibiótico.

Fonte: Próprio Autor.

Entretanto, 75\% do total dos entrevistados alegaram dos concluintes alegaram que houve prescrição médica, que fizeram seu uso nos últimos 12 meses. Com isso, desses $75 \%, 38,9 \%$ dos ingressantes disseram que o medicamento foi prescrito por um médico e $56,7 \%$ o que corresponde, em sua totalidade, que $37,8 \%$ usaram mais que 4 vezes em um período de 12 meses; conforme representado na Figura 5 e Figura 6.

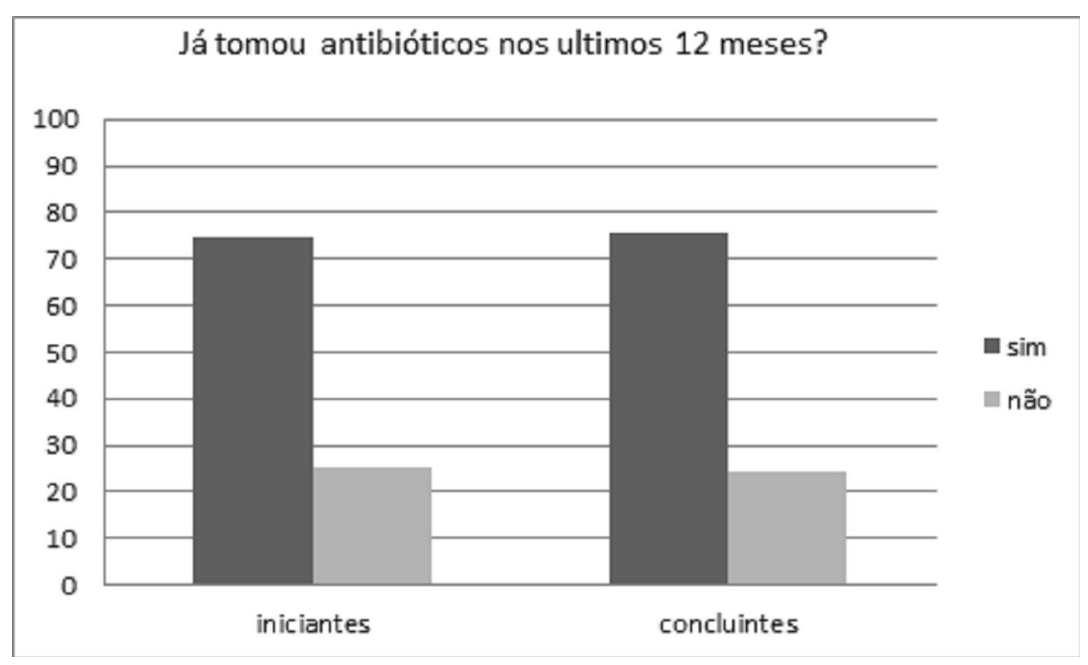

Figura 5 - Comparação sobre o uso do antibiótico nos últimos 12 meses.

Fonte: Próprio Autor. 


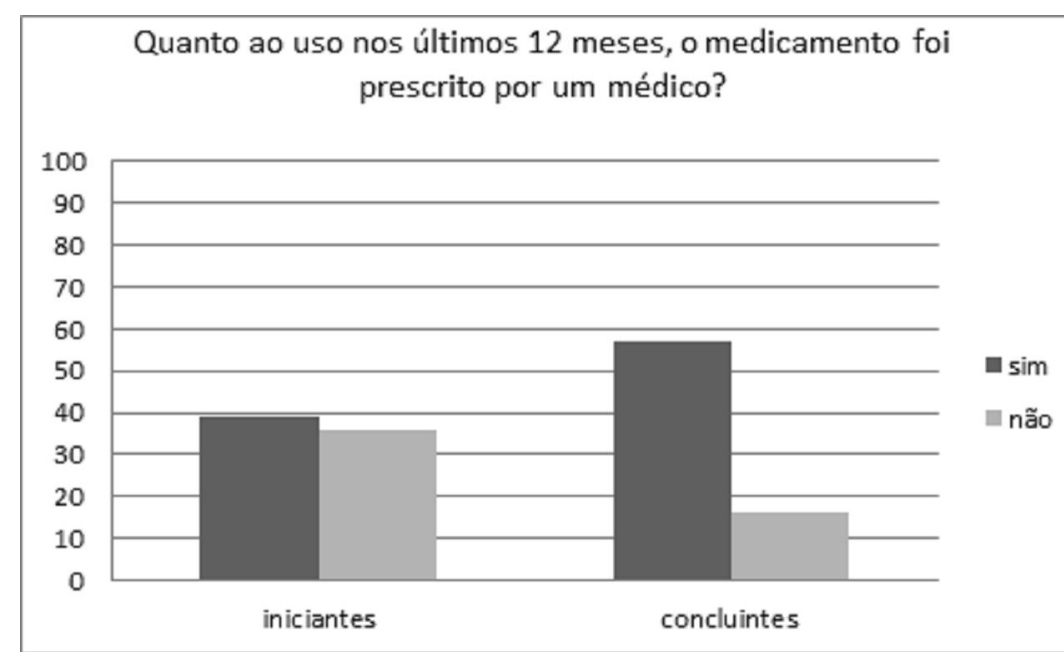

Figura 6 - Comparação sobre a quem prescreveu o uso do antibiótico nos últimos 12 meses.

Fonte: Próprio Autor.

O Quadro 1 demonstra a porcentagem de indivíduos ingressantes e concluintes que mantêm o antibiótico em casa para consumo.

\begin{tabular}{|l|l|l|}
\hline Antibiótico Disponível \Alunos & Ingressantes (\%) & Concluintes (\%) \\
\hline Sim, sempre tem em casa. & $38 \%$ & $24 \%$ \\
\hline $\begin{array}{l}\text { Não, mas compro quando acho que } \\
\text { preciso. }\end{array}$ & $22 \%$ & $24 \%$ \\
\hline Vou ao médico e compro o prescrito. & $38 \%$ & $51 \%$ \\
\hline
\end{tabular}

Quadro 1 - Comparação entre disposição do antibiótico na própria residência.

Fonte: Próprio Autor

Para os ingressantes do curso, através desses dados, percebe-se que há equivalência entre a procura do profissional adequado para prescrição do medicamento como também sempre mantê-lo na sua residência. De modo contrário, mais da metade dos concluintes demonstram procurar e sempre seguir a orientação do médico, não fazendo referência, novamente, ao trabalho de Pinto et al., 2008; que diz o conhecimento teórico-prático influencia na automedicação. Não se confirma esta teoria devido ao maior número de ingressantes no curso de biomedicina alegarem que fazem o autoconsumo, enquanto para os concluintes este número tem-se mostrado decadente. Entretanto, $86 \%$ dos ingressantes e $91,8 \%$ dos concluintes disseram saber os perigos da automedicação, sendo contraditório ao número de indivíduos que a praticam. Um dado de grande relevância se mostra na questão 11 , na qual $88 \%$ dos alunos esperam obter conhecimento que ajude na prática da automedicação; assim, 89\% dos ingressantes alegaram que acreditam obter informações durante a graduação que irá auxiliá-los na autoescolha. 
Isso se repete entre os concluintes, que corresponderam a 86\%. Essa informação se torna importante devido à sinceridade apresentada pelos concluintes, que até então demonstraram uma certa aversão à esta prática; porém, não se pode afirmar que, por mais interessados que estejam na farmacologia, imunologia e microbiologia, que são apresentadas mais complexamente no último período, utilizarão essas informações sem consultar o profissional capacitado; assim, poderá ser de grande valia para exercer um diálogo médico-paciente adequado para a escolha do melhor medicamento para o quadro clínico apresentado.

Conclui-se que os perigos da automedicação são fornecidos nas disciplinas de microbiologia e farmacologia, disciplinas estas ainda não cursadas pelos ingressantes e desconhecidas pela população em geral, que faz a automedicação pela falta de conhecimento. Nesta amostra populacional, visualizou-se as influências que levam à essa prática, ou seja, os familiares, farmacêuticos ou funcionários da farmácia e de prescrições antigas que representam todas as formas de coerção que a população de modo geral pode sofrer. Para reverter esse quadro, é necessária uma maior exposição na mídia sobre práticas educativas quanto aos riscos, benefícios, além de explicações sobre bactérias multirresistentes.

\section{REFERÊNCIAS}

AQUINO, D. S.; BARROS, J. A. C.; SILVA, M. D. P. A automedicação e os acadêmicos da área de saúde. Rev. Ciência e Saúde Coletiva, v. 15, p. 2533-2538, 2010.

BRASIL. Automedicação. Disponível em: <http:// www.anvisa.gov.br/propaganda/folder/ uso_indiscriminado.pdf>. Acesso em 03 de jun. 2013.

RECEBIDO EM 20/7/2014

ACEITO EM 7/11/2014
CUNHA, E. R. et al. Eficácia de três métodos de degerminação das mãos utilizando gluconato de clorexidina degermante (GCH 2\%). Rev. Esc. Enferm. USP, v.45, n.6, p. 1440-5, 2011.

ESTEVAM, A. Higienização insana: sabonetes bactericidas. Disponível em: http://contracultura de bolsoworldpress.com/2012/06/

08higienizacaoinsanasabonetesbactericidas.>Acesso em 21 mar. 2014.

\section{LAKATOS, E. M.; MARCONI, M. de A.}

Fundamentos de metodologia científica. Rev.Ampl. São Paulo: Atlas, 4. ed. 288p, 2001.

LESSA, M. A.; BOCHNER, R. Análise das internações hospitalares de crianças menores de um ano relacionadas a intoxicações e efeitos adversos de medicamentos no Brasil. Rev. Bras.

Epidemiol.,São Paulo, v. 11, n. 4, 2008.

NICOLINI, P. et al. Fatores relacionados à prescrição médica de antibióticos em farmácia pública da região Oeste da cidade de São Paulo. Rev. Ciênc. saúde coletiva, vol.13, p. 689-696, 2008.

OLIVEIRA, C. M.; ANDRADE, A. M. G.; FERNANDES, T. R. M. D.; LAGO, G.; GARCIA, R.; Levantamento da ocorrência de automedicação no município de Itajubá. Revista Brasileira de Medicina. Rio de Janeiro, v.62, p.142-145, 2004.

PINTO, F. C. et al. Automedicação em Acadêmicos do Curso de Enfermagem. 2008. 60f. Trabalho de Conclusão de Curso (Graduação em Enfermagem) - Universidade Presidente Antônio Carlos. Minas Gerais, 2008. 